\title{
Nuevas medidas de protección legal de personas con discapacidad: la asistencia
}

\section{New measures of legal protection for persons with disability: assistance}

\section{Palabras clave}

Asistencia, protección legal, apoyos, vida independiente, derechos, autodeterminación.

\section{Keywords}

Assistance, legal protection, supports, independent living, rights, selfdetermination.

\section{Introducción: sobre la capacidad legal y la protección de las personas con discapacidad}

Tradicionalmente, las figuras de protección para personas con discapacidad aplicadas en la mayoría de las legislaciones de nuestro entorno se han inspirado en el derecho romano. Este presuponía para todas aquellas personas a las que no se les reconocía capacidad suficiente, la necesidad de ser representadas, normalmente por el "pater familias" o cabeza de familia, que era quien tomaba las decisiones en nombre de la persona en cuestión.

Esta forma de representación es la que se ha venido usando en nuestro derecho civil y en los de nuestro entorno.

Nuestro sistema presupone la capacidad de toda persona. Bajo esta presunción, nuestro ordenamiento jurídico sitúa las declaraciones de incapacidad (ahora modificaciones de capacidad) en el ámbito judicial. Es decir, será un juez quien determine si una persona necesita protección en la toma de decisiones y el grado de esta protección.

El sistema de protección de personas con discapacidad que no tienen

\author{
Josep Ruf i Aixàs \\ <pruf@fcsd.org> \\ Fundación Catalana Síndrome de \\ Down
}

\section{Josep Tresserras Basela} $<$ tresserras@somfundacio.org>

Som - Fundació Catalana Tutelar Aspanias

Para citar:

Ruf, J. y Tresserras, J. (20I 5):

"Nuevas medidas de protección legal de personas con discapacidad: la asistencia”, Revista Española de Discapacidad, 3 (I): 193-209.

Doi: <http://dx.doi.org/I0.5569/23405IO4.03.OI.II> 
capacidad suficiente en la toma de decisiones, presupone confirmar que la discapacidad sea incapacitante y es en esa situación en la que la persona debe tener a alguien, persona física o jurídica, que tome decisiones por ella. Esto lo que se denomina toma de decisiones por sustitución.

Pero nuestro ordenamiento civil presenta algunos matices:

- $\quad$ Por un lado, la modificación de la capacidad establece que a las personas que no tengan capacidad suficiente se les nombre un tutor, que deberá tomar decisiones en su nombre. En este caso será por sustitución.

- Por otro lado, en el caso de aquellas personas a las que el juez estime capacidad de comprensión con ayuda, la modificación de la capacidad será relativa y estará sometida a su curatela. En estos casos la persona conservará parcialmente su capacidad, en las áreas que el juez estime oportunas. Para que las decisiones que tome la persona, en las áreas en las que necesita apoyo, tengan validez, deberán ser consensuadas entre la persona y su curador.

Nuestro derecho civil obliga a los jueces a adecuar las sentencias de modificación de capacidad a las necesidades reales de cada persona, o lo que se ha denominando "hacer un traje a medida”. Esta práctica permite ofrecer los apoyos adaptados a las necesidades individuales reales. Se entiende que de algún modo, un buen uso de esta adecuación de la protección acerca estas prácticas a los requerimientos de la Convención Internacional sobre los Derechos de las Personas con Discapacidad de Naciones Unidas (ONU).

El artículo I 2 de esta Convención reafirma que las personas con discapacidad tienen derecho al reconocimiento de su personalidad jurídica, en igualdad de condiciones con las demás personas y en todos los aspectos de la vida. Por ello, se deben adoptar las medidas necesarias para proporcionar los apoyos que puedan requerir en el ejercicio de su capacidad jurídica, con las salvaguardas adecuadas y efectivas que impidan abusos y velen por sus derechos, voluntades y preferencias.

En este sentido, muchos países han empezado a revisar sus marcos legales para adaptarlos a los principios de la Convención y se están haciendo algunos avances, pero aún dista mucho de conseguir una regulación homogénea. La principal dificultad al respecto ha sido que desde la aprobación de la Convención en el año 2006 los distintos países que la han ido ratificando han interpretado el artículo I 2 de distinta manera, hecho que dificulta su aplicación. Por este motivo, el I I de Abril de 20I4 el Comité sobre los derechos de las personas con Discapacidad aprobó la Observación general $n^{\circ}$ I 20I4 sobre el Artículo I2: Igual reconocimiento como persona ante la ley. ${ }^{\mathrm{I}}$

En el documento se interpreta el artículo I 2, para despejar las dudas que puedan surgir en su aplicación por los Estados parte, dejando claro que el nuevo paradigma, según dicho artículo, se basa en los apoyos que deben recibir las personas para la toma de decisiones. Este documento va a obligar a los distintos países que han ratificado la Convención a adoptar las medidas necesarias para adaptar les legislaciones o al menos a posicionarse al respecto. También debemos de tener en cuenta la recomendación $\mathrm{n}^{\circ} 99$ (4) del Comité de Ministros del Consejo de Europa, del 23 de febrero de I999, relativa a los principios de protección jurídica de personas adultas incapaces, basada en principios como: la mínima intervención, la subsidiaridad, la flexibilidad, la individualización, la proporcionalidad de las medidas, el respecto y la promoción de la autonomía.

I. Comité sobre los derechos de las Personas con Discapacidad. I I ${ }^{\circ}$ período de sesiones. 3 I de marzo a i I de abril de 20I4. Observación General No I (20I4). Artículo I 2: Igual reconocimiento como persona ante la ley. 


\section{Aparición de la asistencia como figura de protección legal en Catalunya}

La ley $25 / 2010$, del 29 de Julio, del libro $2^{\circ}$ del Código Civil de Catalunya, mantiene las instituciones de protección tradicionales existentes (tutela, curatela, defensa judicial, etc.) y regula otras nuevas, como la figura de la asistencia, con el objetivo de dar respuesta a la diversidad de situaciones en las que pueden encontrarse las personas con discapacidad.

La ley pretende reforzar la autonomía personal de las personas, flexibilizando la respuesta jurídica y evitando, en la medida de lo posible, procedimientos de modificación de capacidad innecesarios y/o desproporcionados para las necesidades reales de algunas personas. No debemos olvidar que estos procesos someten a las personas y a sus familias a unos procedimientos, a menudo, largos y dolorosos debido a su naturaleza y su complejidad.

Esta ley se enmarca en los principios de la Convención Internacional sobre los Derechos de las Personas con Discapacidad de Naciones Unidas (2006), que defiende y propugna un modelo de protección legal que respete al máximo la autonomía de la persona y que determine los apoyos que esta necesitará, en función de sus necesidades. De todos modos, debemos de tener en cuenta que seguirán existiendo situaciones en las que no será posible conocer la voluntad de la persona o en las cuales habrá que decidir por ella para protegerla adecuadamente.

La figura de la asistencia tiene distintos antecedentes en derecho comparado, como el modelo normativo alemán de asistencia. Hasta el año I99I, en Alemania operaba la incapacitación de la persona (Entmündigung) seguida del nombramiento de tutor, con unas facultades similares a las propias de la tutela de menores de edad. En el año I 990 se instaura un modelo que pone el acento en la necesidad de proteger a la persona sin cambiar su estado civil. Esta ley derogó las causas de incapacitación, abolió el procedimiento de incapacitación y la distinción entre grados de incapacidad. La tutela y curatela de mayores de edad se sustituyeron por un único régimen, denominado asistencia (Betreuung) que prevé que una persona puede necesitar protección para gestionar sus propios asuntos, siempre a instancia propia.

Otro modelo de referencia proviene del derecho francés, que contempla un régimen de protección para personas que no puedan gestionar sus propios intereses, pero en unas condiciones basadas estrictamente en la alteración de las facultades mentales o corporales, probadas médicamente, que impidan le expresión de la voluntad de la persona. La autoridad judicial es la encargada de determinar la mejor protección para la persona, incluyendo la tutela y la curatela.

Por lo tanto, tenemos referencias de países en los que las medidas de protección legal siguen basándose en la incapacitación legal, con el ejercicio de la tutela o la curatela, otros donde la asistencia coexiste con dichas medidas y otros países donde las ha sustituido.

\section{Presentación del proyecto de colaboración}

La aparición de la asistencia hace necesario empezar a planificar estrategias de difusión y aplicación de esta nueva medida de protección legal de las personas con discapacidad en Catalunya. Es preciso que las personas con discapacidad, sus familias y los profesionales o servicios que los orientan en sus decisiones vitales, conozcan esta alternativa que preserva la capacidad jurídica de la persona. Pero necesitamos disponer de experiencias reales de aplicación de la asistencia que confirmen su adecuación y viabilidad como medida de protección.

Por este motivo, SOM-Fundación Catalana Tutelar Aspanias y la Fundación Catalana 
Síndrome de Down (FCSD) diseñaron un proyecto conjunto que sirviera para experimentarla con personas con discapacidad intelectual. Colaboraciones anteriores entre las dos entidades favorecieron este proyecto con objetivos como:

- Difundir la máxima información sobre la asistencia.

- Analizar las condiciones más favorables de aplicación de esta medida.

- Diseñar un protocolo para su tramitación y aplicación.

- Desarrollar una metodología de trabajo.

- Experimentar la idoneidad de los casos susceptibles de beneficiarse de la figura de la asistencia.

- Analizar resultados de su aplicación real.

Cabe decir, que desde el año 2002 empieza a consolidarse en Catalunya la opción de vida independiente para muchas personas con discapacidad intelectual, como alternativa a la convivencia familiar y a su institucionalización en servicios residenciales. Esto se debe a la creación de servicios de apoyo personal en sus domicilios y en la comunidad, regulados a través de una nueva prestación social denominada "Programa de apoyo a la autonomía en el propio hogar" del Departamento de Bienestar Social y Familia de la Generalitat de Catalunya, del cual se benefician I 200 personas actualmente.

Previamente, la FCSD pone en marcha, en el año 2000, con carácter pionero en el Estado Español, el primero de estos servicios que ha evidenciado la viabilidad de una opción de vida autónoma o la capacidad de autogobierno de estas personas, con los apoyos adecuados, indistintamente de su situación personal, social y legal.

La experiencia en el seguimiento y apoyo a los proyectos vitales de estas personas, confirma que sumando los apoyos formales de los servicios con los apoyos naturales de los que disponga la persona (familia, vecinos, amigos, etc.) se atienden y resuelven la mayoría de necesidades personales que implica una vida autónoma. Pero el verdadero fomento de la autonomía personal también presenta, a menudo, dilemas técnicos y éticos. Especialmente, en el caso de personas sin referentes naturales significativos, que concentran sus demandas de orientación en decisiones personales y patrimoniales al servicio de apoyo. A menudo estas situaciones pueden favorecer un excesivo intervencionismo por parte de los profesionales, creando relaciones de dependencia injustificadas y sobrepasando los límites de neutralidad de los apoyos ofrecidos.

Algunos ejemplos prácticos se han dado ante demandas tales como pedir orientación en la elaboración de actos testamentarios, donaciones, consejo en operaciones financieras, de compraventa o en la gestión del propio patrimonio, solicitud de delegación de decisiones médicas actuales o futuras, etc.

En muchos de estos casos, estas demandas cursaban con funcionamientos personales lo suficientemente autónomos, con capacidad de pedir ayuda y sin señales de vulnerabilidad que pudieran justificar objetivamente la necesidad de instar un una medida de protección legal convencional.

La aparición de la asistencia supuso una alternativa que ofrece nuevos apoyos, perfectamente compatibles con los existentes y totalmente legítimos, dada su naturaleza y reconocimiento legal. Es en este contexto que surge la idea de iniciar este proyecto de colaboración.

\section{Entidades colaboradoras}

Sóm-Fundación Catalana Tutelar Aspanias (SÓM-FCTA) es una entidad tutelar creada el año I987, referente y pionera entre las entidades tutelares a nivel estatal y autonómico, inscrita en el Registro de Fundaciones de la Generalitat de Catalunya con el número 327 y que en la actualidad cuenta con 504 tutelas en ejercicio. 
La misión de esta entidad es velar para que las personas con discapacidad psíquica y del desarrollo dispongan de las ayudas y apoyos necesarios para poder desarrollar su proyecto personal a lo largo de su vida. Sus valores son:

- Compromiso y responsabilidad social: con las personas que tutela y con la sociedad en general a fin de identificar y hacer visible el desarrollo de los derechos sociales y exigir una responsabilidad pública y social. Los criterios en los que se basa para conseguirlo son: personalización, acompañamiento, integridad, justicia y humanismo.

- Transparencia: en la administración de las cuentas y patrimonio, en general, tanto de la entidad como de las personas tuteladas, con el rigor y los principios generales contables supervisados por los órganos pertinentes (Protectorado, Administración, Fiscalía, etc.). Los criterios en los que se basa la gestión son: eficacia, eficiencia, profesionalidad, austeridad e innovación.

- Independencia: A fin de garantizar el control de la calidad de vida y el bienestar de las personas tuteladas, la entidad no presta servicios asistenciales: residenciales, laborales, educativos, etc., para no perder objetividad en la defensa de sus derechos e intereses. Los criterios en los que se basa son: objetividad, subsidiariedad y no discriminación.

- Confianza: entendemos la confianza de las familias, de los tutores de las personas con discapacidad intelectual, así como de las entidades sociales y las administraciones públicas, junto con la proximidad, la empatía, la personalización y el reconocimiento como valores básicos de nuestra actividad y objetivos.

La Fundación Catalana Síndrome De Down (FCSD) es una entidad privada, sin ánimo de lucro, constituida en I984, declarada de utilidad pública e inscrita en el Registro de Fundaciones de la Generalitat de Catalunya con el número 6I.
Nacida como la iniciativa de un grupo de familias y profesionales con el objetivo de profundizar sobre el síndrome de Down (SD) y otras discapacidades intelectuales, a través de la investigación y la experiencia práctica en los campos de la pedagogía, la psicología, la medicina y el área social y contando con la participación de científicos internacionales. Su carácter pionero constituye un punto de referencia para entidades públicas y privadas, nacionales e internacionales.

\section{A lo largo de estos años la FCSD ha} desarrollado programas y servicios que atienden las necesidades de las personas y de sus familias a lo largo de todas las etapas vitales, desde la primera infancia hasta la vejez, siempre con el objetivo de hacer posible la plena inclusión social en todos entornos sociales ordinarios. $\mathrm{Su}$ actividad se basa en principios y valores como:

- Derechos humanos: reconocidos en la Declaración Universal de los Derechos Humanos (I948) y la Convención de Derechos de la Persona con Discapacidad de la ONU.

- Concepto de discapacidad de la OMS: que entiende la discapacidad como la consecuencia de la interacción entre las condiciones de salud, los factores personales y las condiciones ambientales.

- Normalización: para promover el cambio social y acciones inclusivas.

- Autogestión: las personas son sujetos activos y capaces de gestionar su propia vida con el apoyo individualizado necesario.

- Apoyo a las familias: como referente principal en la trayectoria vital de estas personas.

- Atención Integral: basada en un modelo bio-psicosocial.

- $\quad$ Salud: la definición de la OMS la entiende como el estado de bienestar físico, psicológico y social.

- Inclusión: una sociedad justa cree en la igualdad de oportunidades, la no discriminación y la diversidad como fuente de riqueza.

- Educación: los alumnos con discapacidad tienen derecho a ser escolarizados en 
centros educativos ordinarios y a recibir una educación personalizada.

- Vida independiente: derecho a decidir dónde y con quién quieren vivir, a disponer de los apoyos necesarios (formales y naturales) y de unas políticas de vivienda accesible y asequible.

- Capacidad legal: el goce y ejercicio de derechos y deberes.

- Empleo y formación profesional: derecho al mercado laboral ordinario, con los apoyos necesarios y una formación profesional continua que les promocione.

- Ocio y tiempo libre: inclusivo, normalizado y que fomente la autodeterminación.

- Investigación: liderar la innovación y la divulgación de los avances biomédicos y psicosociales sobre el síndrome de Down y la discapacidad intelectual.

- Gestión eficiente: de los recursos públicos o privados y su reparto equitativo. La transparencia en las actividades, las cuentas de resultados y los balances.

- Seguimiento y evaluación de nuestros servicios: garantizar una respuesta adecuada a las necesidades cambiantes de las personas y de la sociedad, y conseguir la mejora continua en la calidad de nuestro sistema de gestión.

- Equipo humano: un equipo humano multidisciplinario, comprometido con la misión de la Fundación, sus principios y sus valores.

La FCSD defiende un mundo en el cual las personas con discapacidad participen de forma plena en la sociedad, en igualdad de condiciones que el resto de la población. Y trabaja para mejorar la calidad de vida de estas personas, facilitando su total inclusión social y la consecución del máximo grado de bienestar, autodeterminación, desarrollo personal, respeto y dignidad.

La participación de la FCSD en el proyecto piloto de aplicación de la asistencia se gestiona desde el servicio de apoyo a la vida independiente "Me voy a casa" que atiende a personas con discapacidad intelectual que han accedido a una vida autónoma, emancipándose de sus familias o de un servicio residencial. Cada persona decide y crea su propia unidad de convivencia (solos, en pareja o con algún amigo) $\mathrm{y}$ accede a una vivienda propia, en régimen de alquiler o propiedad.

Para llevar a cabo esta experiencia piloto, se creó un equipo de colaboración entre ambas entidades compuesto por:

- SOM-FCTA: trabajadora social y abogado asesor financiero que coordinarían la acogida de los solicitantes, la tramitación de la demanda y la provisión de la asistencia.

- FCSD: educador social, personas de apoyo y pedagogo, como referentes de la derivación de los solicitantes y la posterior coordinación entre las tareas de apoyo con las de la asistencia.

\section{Definición de la asistencia}

La propia regulación de la asistencia, establece que la persona mayor de edad que lo necesite, para tener cura de ella misma o de sus bienes, debido a una discapacidad no incapacitante de sus facultades físicas o psíquicas, podrá solicitar a la autoridad judicial el nombramiento de un asistente (Capítulo VI , Libro $2{ }^{\circ}$ CCC , artículo 226-I del Código Civil).

La asistencia es concebida como un medida de protección a disposición de las personas para las cuales, por sus condiciones psicofísicas, la incapacitación y la tutela no son posibles, ni siquiera aconsejables. La ley pone énfasis en la capacidad natural de las personas y en el respecto a su autonomía en el ámbito personal y familiar.

La asistencia se da en un procedimiento de Jurisdicción voluntaria en el que es necesaria una resolución judicial, en la que el juez determine el ámbito: personal y/o patrimonial. La autoridad judicial tiene que respetar la voluntad de la persona a la que se debe asistir 
en cuanto al nombramiento o la exclusión de alguna persona para ejercer la función de asistencia (Capítulo VI Artículo 226-2).

\section{Finalidad de la asistencia}

La asistencia tiene la finalidad de proporcionar la ayuda, ofrecer apoyos (acompañamiento, consejos, orientación, asesoramiento...) y velar para que la persona acceda a la información de los asuntos que le incumben de manera adecuada, con el fin de lograr el cuidado de sí misma o de sus bienes y así prevenir riesgos por parte de terceras personas.

Como sistema de apoyos, desde el principio es controlado por la propia persona, actúa a petición de la misma y en ningún caso sustituye sus propias voluntades.

7. Perfil de los candidatos del proyecto piloto

Dada la inexistencia de experiencias previas y con el objetivo de facilitar al máximo la aplicación experimental de esta nueva figura de protección, se definieron unas características personales de inclusión en el proyecto piloto para los posibles candidatos/as.

Estas características obedecen a dos circunstancias determinantes de la puesta en parcha del proyecto piloto:

- Las características personales de los usuarios del servicio de apoyo a la vida independiente que determinaba unas situaciones de origen con necesidades y demandas previas detectadas.

- La necesidad de garantizar la comprensión y aceptación de la asistencia por parte de la propia persona.
De esta manera se establecieron unos criterios de inclusión de posibles candidatos al proyecto:

- Presentar una discapacidad intelectual ligera o inteligencia límite que facilitara la comprensión del proyecto.

- Baja incidencia de trastorno mental en las capacidades volitivas de la persona.

- Conciencia de las propias limitaciones y de la necesidad de apoyo para garantizar la demanda explícita de ayuda.

- Actitud manifiesta de colaboración con aquellos agentes referentes de la persona y con el equipo del proyecto.

- Residencia en Catalunya para poder beneficiarse de los recursos legales y sociales propios del territorio, ya que fuera de Catalunya la medida no es aplicable por ser derecho civil autonómico.

- Mayoría de edad como requisito para la plena capacidad jurídica de decisión.

Estas variables no respondían a un único perfil de solicitante sino que debían ser valoradas en las circunstancias individuales de cada caso. Pero, en cualquier caso, debían garantizar las competencias necesarias para participar y argumentar el proceso legal que supone tramitar una demanda de asistencia.

Uno de los objetivos del análisis de resultados de este proyecto piloto sería revisar posteriormente estos perfiles para estudiar su confirmación, ampliación e introducir las modificaciones necesarias.

\section{8. Ámbitos y funciones de la asistencia}

En las resoluciones de nombramiento de asistencia, la autoridad judicial determina los apoyos y los intereses de los que debe tener cura el asistente en los ámbitos personal y/o patrimonial, de acuerdo con lo expresado en la demanda inicial y lo establecido en la ley: 
7.I. Esfera personal: el asistente debe velar por el bienestar de la persona asistida, respetando plenamente la voluntad y las opciones personales. Corresponde al asistente recibir la información y dar el consentimiento, si la persona asistida no puede decidir por ella misma sobre la realización de actos, tratamientos médicos y no ha otorgado un documento de voluntades anticipadas.

Por encima de lo que dice la ley, entendemos que en la esfera personal el asistente, si así lo quiere la persona, puede ofrecer un seguimiento más global para detectar, orientar y apoyar, no sólo en cuanto al bienestar físico, sino también en otras áreas como las del bienestar emocional, desarrollo personal, relaciones interpersonales, inclusión social, derechos y autodeterminación y puede intervenir en las incidencias que se puedan producir dentro de estas áreas y que pongan en riesgo el bienestar personal del asistido, realizando así una acción preventiva. Este seguimiento deberá respectar siempre las voluntades de la propia persona.

Principalmente, los apoyos en la esfera personal harán referencia a: la toma de decisiones para el logro del bienestar personal, toma de decisiones y otorgamiento de consentimiento informado para cualquier intervención o tratamiento médico, con especial atención a los tratamientos psiquiátricos, psicológicos y/o farmacológicos; toma de decisiones relativas a la actividad laboral, al ámbito doméstico con especial incidencia en el mantenimiento del domicilio, la alimentación y la higiene personal y que pueda conservar el derecho de sufragio electoral.

8.2. Esfera patrimonial: El asistente debe intervenir, junto con la persona asistida, en los actos jurídicos relacionados con las funciones de la asistencia. A petición de la persona asistida, la autoridad judicial también puede conferir al asistente funciones de administración del patrimonio de la persona asistida (Artículo 226-2). Los actos jurídicos que la persona asistida haga sin la intervención del asistente, si esta fuera necesaria, serán anulables.
Una vez definido lo que dice la ley, entendimos que el asistente, si así lo requiere la persona asistida, puede ofrecer información, apoyo, intervenir junto con ella en todos los actos que pida.

Algunos ejemplos: actuaciones referidas a la administración de su sueldo y patrimonio, adquirir bienes, alquilar una vivienda, disponer de bienes inmuebles y muebles, contratar préstamos o compromisos de pago diferidos, establecer hipotecas, cargas sobre inmuebles o sobre patrimonio, contratar operaciones bancarias o financieras que supongan compromisos patrimoniales, sea cual sea su alcance temporal o cuantitativo, realizar disposiciones para decidir sobre su patrimonio, sin perjuicio de que pueda disponer de dinero para sus gastos personales por valor del importe que fije su asistente, que informe de la decisión a la entidad bancaria donde perciba sus ingresos.

Entendemos que tanto si se trata de intervenir en la esfera personal como en la patrimonial es imprescindible establecer un vínculo y una relación con la persona basada en la confianza y el respeto mutuo.

\section{Tramitación de la asistencia}

Para acceder a esta medida de protección legal, es necesario formular y presentar una demanda de nombramiento de asistente en el Juzgado correspondiente al domicilio de la persona que lo solicita.

Cabe decir que en los casos derivados y/o atendidos dentro del proyecto piloto, la demanda es formulada por la propia persona acompañada por los servicios legales de la entidad tutelar.

Una vez presentada la demanda, el juez cita al presunto futuro asistido, donde también intervendrá el ministerio fiscal y el médico forense que deberán confirmar que la persona presenta una disminución no incapacitante. 


\section{Protocolo de aplicación del proyecto piloto}

\subsection{Fase de acogida:}

Los solicitantes pueden acceder al proyecto a través de tres vías:

- Por propia demanda de la persona y/o familia: la entidad tutelar recibe una primera demanda directa de información y planifica todas las entrevistas necesarias de cada fase.

- Por derivación desde un servicio o profesional derivantes: el derivando (en este caso, Servicio de apoyo a la vida independiente "Me voy a casa" de la FCSD) formula una hipótesis de demanda a la entidad tutelar, envía la documentación requerida y planifican una primera reunión conjunta de valoración de la derivación. La entidad tutelar abre el expediente individual de asistencia (EIA)

- Petición a la entidad tutelar por parte del órgano judicial.

\subsection{Fase de valoración:}

- Traspaso de la documentación requerida del servicio derivante a la entidad tutelar (Fotocopia DNI, reconocimiento discapacidad, valoración dependencia, informes médicos, psicológicos, etc.).

- Primera reunión de derivación entre la entidad tutelar y el servicio derivante para valorar, confirmar la derivación del caso.

- Primera entrevista de presentación de la persona interesada acompañada por el agente derivante para recibir información de la entidad tutelar y de la asistencia. En esta entrevista se empieza a recoger información de la persona interesada y a sondear su demanda hipotética inicial.

- Visita en el domicilio de la persona interesada con el objetivo de conocer y valorar el estado del entorno de la persona y clarificar algunas informaciones proporcionadas de la asistencia, ello permite confirmar su comprensión y atender dudas.

- Entrevistas entre la persona interesada y la entidad tutelar para que pueda formular, con toda la información de la que dispone y sin ninguna influencia externa, sus propias consultas y así confirmar su demanda de asistencia. Esta fase concluye con la redacción de una propuesta de asistencia que concretará las voluntades de la persona y permitirá derivar el caso a los servicios legales de la entidad tutelar.

- Entrevista de devolución y derivación a los servicios legales para confirmar la demanda formulada en la propuesta de asistencia realizada por parte de la entidad tutelar y derivar el caso al área jurídica de la entidad tutelar que iniciará toda la tramitación.

\subsection{Fase de tramitación}

Los servicios jurídicos de la entidad tutelar redactan junto con la persona solicitante la demanda de asistencia que presentarán ante el órgano judicial y que se acompaña de la documentación necesaria para su tramitación, que acredite la discapacidad de la persona y un certificado médico o psicológico que acredite sus capacidades cognitivas y volitivas, así como que se trata de una discapacidad no incapacitante.

La tramitación de la demanda incluye todas las acciones que los servicios jurídicos de la entidad tutelar tendrán que gestionar con la persona interesada hasta llegar a la aprobación y nombramiento del asistente por parte del juez. La FCSD realiza un seguimiento del proceso con el usuario y se coordina con la entidad tutelar para garantizar que la persona solicitante dispone y comprende toda la información del proceso.

\subsection{Nombramiento}

La resolución judicial confirma los ámbitos de asistencia y el nombramiento del asistente de acuerdo con lo establecido en la demanda presentada y según define la ley. El 
nombramiento debe ser inscrito en el Registro Civil para que sea efectivo.

\subsection{Fase de aplicación de la asistencia}

Una vez finalizada la tramitación y nombramiento del asistente, se inicia propiamente la aplicación de la asistencia como medida de apoyo y protección legal.

I. Entrevista de inicio de la asistencia con la persona interesada, ahora ya asistida, para informarle del nombramiento, elaborar el pacto de asistencia de acuerdo con la resolución judicial y así planificar el inicio de la asistencia.

2. Entrevistas de seguimiento que se consideren necesarias para coordinar todas aquellas demandas, incidencias y necesidades surgidas.

3. Actualización anual del Plan de Asistencia con todos los agentes principales decididos por la persona asistida.

\section{Metodología de la asistencia}

Partimos de una absoluta voluntariedad y conciencia de dificultades específicas, detalladas en la demanda, por parte del propio asistido, como base de una relación de confianza que permitirá al asistente asesorar, informar y orientar sin ningún interés individual sobre las decisiones y conveniencias del asistido.

El asistente se reúne con el presunto asistido las veces que haga falta, siguiendo las orientaciones del protocolo, para llegar a acuerdos y hacer la compilación de la información necesaria.

La premisa es detectar demandas, necesidades y dificultades a nivel personal y/o patrimonial que motiven la demanda de la persona. Con la información de las entrevistas y de la documentación aportada (informes sociales, médicos, etc.) se valora la idoneidad y adecuación de la figura de la asistencia al solicitante.

La empatía con cada situación personal y la escucha activa permiten conocer cuáles son las expectativas del presunto asistido para encuadrar aquellos aspectos relevantes de su vida y adaptar la ayuda de la asistencia. A partir de la aceptación inicial se definen conjuntamente los objetivos específicos de cada ámbito (personal y patrimonial).

La asistencia requiere de una relación cercana y continuada a través de visitas periódicas o llamadas telefónicas que permitirán hacer el seguimiento de la evolución de los objetivos planteados. Es importante que la persona asistida entienda que se trata de una figura que asesora y acompaña puntualmente en las situaciones previstas o ante una demanda concreta.

Ante situaciones de angustia, estrés emocional o de desconcierto, el asistente procurará el apoyo emocional que disminuya la percepción negativa o de conflicto, destacando las competencias personales y las ventajas de la relación de ayuda que permite encontrar las soluciones necesarias.

El plan de trabajo debe atenerse a lo dispuesto por la sentencia judicial, si bien, a medida que avance la asistencia se irán adaptando las estrategias a las necesidades que vayan surgiendo.

Es imprescindible mantener un clima de absoluta confianza que aporte a la relación el marco referencial de la asistencia y facilite el intercambio de opiniones, deseos y pensamientos.

La finalidad de la asistencia será potenciar las habilidades, actitudes, recursos personales y comportamientos de la misma persona asistida para dotarla de nuevas herramientas que mejoren su autonomía y su adaptación al entorno, que lo permitan funcionar en las condiciones previstas a su plan de trabajo.

Es imprescindible la sinceridad y transparencia para aportar el máximo de información fiable 
que permita dar y buscar las propuestas que mejoren la calidad de vida de la persona.

Otras tareas que desarrolla el asistente incluyen acompañamientos en gestiones, trámites, visitas, reuniones, etc., si se precisa. Y también la observación y la detección de dificultades que obstaculicen su bienestar y su desarrollo.

Así se trabajará para:

- Procurar una relación de confianza y transparencia.

- Potenciar la autonomía personal.

- Mejorar el funcionamiento individual y la adaptación al entorno.

- Complementar las competencias personales, no sustituirlas. "No se trata de entregarle el pescado, sino, más bien, de enseñar a pescar dentro de lo posible.".

- Preservar la autodeterminación de la persona.

- Mantener una escucha activa

- Proporcionar acompañamiento social

- Fomentar la mejora de la calidad de vida

- Prevenir incidencias que pongan en peligro el bienestar y la seguridad personal.

\section{Principios y valores del proyecto piloto de asistencia}

Entendemos por principios aquellas leyes universales, inmutables y válidas para todo el mundo que inspiran la buena conducta personal y social. Destacamos cuatro principios importantes en la asistencia, además de los propios de una relación asistencial que procura el beneficio de la persona, destacamos:

- Principio de inclusión social, como proceso que se orienta para ofrecer a la persona asistida todas las oportunidades y recursos personales para poder desarrollarse y participar plenamente en todos los ámbitos de la vida en la comunidad.
- Principio de autogestión, en su proyecto, en la elaboración de su plan de trabajo o plan de asistencia para influir en su proceso de toma de decisiones y diseño de sus objetivos.

- Principio de corresponsabilidad, como compromiso para cooperar en la construcción de su plan de asistencia, detección de necesidades y voluntad de mejora.

- Principio de respeto a la dignidad, como condición esencial de la asistencia que se ofrece de una manera desinteresada y benefactora.

Atendemos a valores como el bien descubierto y escogido de forma libre, que es buscado y realizado por las personas y que deber ser reconocido por los demás. Al mismo tiempo, la asistencia deberá responder, entre otros, a los valores siguientes:

- El valor del desarrollo humano, para ejercer un rol que favorezca la consecución de objetivos personales, la mejora del crecimiento personal, de las condiciones de vida, con equilibrio entre los derechos y las responsabilidades de la persona.

- El valor de la equidad, que implica un trato justo a todas las personas a partir del reconocimiento, la justicia y la eliminación de cualquier actitud y/o acción discriminatoria.

- El valor de la igualdad, en relación con la eliminación de barreras y perjuicios.

- El valor de la tolerancia, que implica respetar, escuchar y aceptar ideas, opiniones, creencias y prácticas del otro.

13. Derechos y obligaciones de las partes

La regulación de la asistencia establece claramente unos derechos y unas obligaciones para las partes que van a participar de la aplicación de esta medida de protección y de una relación ayuda. 


\subsection{Derechos y deberes de la persona} asistida:

- Derecho a recibir voluntariamente la asistencia.

- Derecho a recibir la información en relación a los aspectos que le incumben.

- Derecho a presentar sugerencias y/o reclamaciones sobre la asistencia para ser valorados.

- Derecho a la intimidad y a la no divulgación de los datos personales que figuren en sus expedientes, a mantener privacidad mediante el secreto profesional de todos los datos personales.

- Derecho a disfrutar de una atención personalizada y continuada.

- Derecho a ser tratado sin discriminación, con el respeto y la consideración debidos a su dignidad, de acuerdo con sus particulares convicciones culturales, religiosas o filosóficas, y a ser tenida en cuenta su situación personal y familiar.

- Obligación de facilitar la percepción de la asistencia y a cumplir los acuerdos establecidos.

- Obligación de asistir a las citas.

- Obligación de comunicar cambios importantes.

- Obligación a mantener actitud colaboradora

- Obligación a informar de datos importantes, destacables y decisivos.

- Obligación de mostrar respeto y sinceridad.

\subsection{Derecho y deberes del asistente:}

- Derecho a comunicar a los órganos pertinentes cualquier situación de riesgo.

- Derecho a expresar una valoración objetiva argumentada ante las situaciones planteadas por el asistido.

- Derecho a orientar las decisiones del asistido para prevenir riesgos o peligros.

- Derecho a anular actos susceptibles de ser anulados, tal y como establece la ley.

- Obligación de trabajar para mejorar la calidad de las decisiones tomadas por la persona asistida.
- Obligación de velar por el buen funcionamiento y orden de los asuntos que se hayan declarado a la demanda.

- Obligación de respetar sus decisiones.

- Obligación de asesorar, informar y dotar de recursos adecuados para cada situación personal consultada.

14. Anulabilidad de los actos de la persona asistida

La ley establece en el artículo 226-3 que los actos jurídicos que la persona asistida haga sin la intervención del asistente, si esta intervención fuera necesaria, son anulables a instancia del asistente o de la persona asistida. También lo son a instancia del tutor, si se constituye tutela, y de los herederos de la persona asistida, en el plazo de cuatro años a partir desde la puesta en tutela o desde su muerte, respectivamente.

15. Modificación de la asistencia (Artículo 226-4)

A instancia de la parte interesada, incluida la persona asistida, la autoridad judicial debe acordar la reducción o la ampliación del ámbito de funciones del asistente si fuera necesario dadas las circunstancias.

Si el asistente tiene conocimiento de circunstancias que permitan la extinción de la asistencia o la modificación de su ámbito de funciones, debe comunicarlo a la autoridad judicial. 


\section{Extinción de la asistencia (Artículo 226-5)}

La asistencia se puede extinguir por las causas siguientes:

a. Por la muerte, la declaración de muerte o de ausencia de la persona asistida.

b. Por la desaparición de las circunstancias que la determinaron.

c. Por la modificación de la capacidad de la persona asistida.

En el supuesto del apartado b), la autoridad judicial, a instancia de parte interesada, debe declarar el hecho que pudiera dar lugar a la extinción de la asistencia que dejaría sin efectos el nombramiento del asistente.

\section{Régimen jurídico (Artículo 226-6)}

Mientras sean compatibles con la función de la asistencia, se aplicaran al asistente las normas de este código en materia de aptitud, excusa y remoción de los tutores, y también las relativas a la rendición de cuentas si el asistente tuviera atribuidas funciones de administración ordinaria del patrimonio de la persona asistida.

18. Publicidad registral (Artículo 226-7)

La asistencia, mientras no se inscriba en el Registro Civil, no es oponible a terceros.

La toma de posesión del cargo de asistente se debe inscribir en el Registro Civil del domicilio de la persona asistida mediante la comunicación de la resolución judicial.

\section{Valoración de solicitantes para el proyecto piloto}

Se seleccionaron tres propuestas de posibles solicitantes, en base a los criterios de acceso al proyecto piloto, junto con la valoración de distintos motivos que argumentaran las propuestas:

Caso A: se trata de una persona de 50 años de edad, con un diagnóstico de inteligencia límite y epilepsia y un grado de disminución reconocido de un $36 \%$, que vive sola desde hace años aunque se derivó al servicio de vida independiente años más tarde, trabaja en un centro especial de empleo como oficial de jardinería para el Ayuntamiento de su ciudad. Debido a algunos antecedentes de conflictiva socio-familiar, no mantiene ninguna relación significativa con sus familiares, con lo que la necesidad de apoyo se concentraba en los servicios de referencia (laboral y vida independiente). El plan de atención personal (PAP) elaborado por el servicio de apoyo a la vida independiente incluía, entre otros, apoyos relacionados con la gestión de la propia salud (seguimientos médicos, atención psicológica, etc.), la gestión de sus bienes materiales (salario y cuentas de ahorro), y la toma de decisiones personales vitales. Con el objetivo de aumentar los apoyos disponibles y de garantizar la máxima neutralidad de estos, se consideró que la asistencia podía suponer una nueva ayuda independiente de los servicios asistenciales y legitimada legalmente.

En el proceso de derivación la solicitante confirmó demandas referidas a:

- Orientación y ayuda para hacer testamento y documento de voluntades anticipadas.

- Ayuda para hacer la declaración anual del IRPF y el seguimiento de los depósitos bancarios.

- Prestar consentimiento informado y manifestaciones de última voluntad, en el caso de hacerlo ella misma, de acuerdo con sus instrucciones verbales, si antes no había 
otorgado un documento de voluntades anticipadas.

- Orientación en momentos personales de angustia en sus relaciones con otras personas.

Caso B: se trata de una persona de 53 años de edad, con un diagnóstico de trastorno de la afectividad y adaptativo, con un grado de disminución reconocido del $40 \%$, que trabaja como reponedora en unos grandes almacenes y comparte piso con un amigo desde hace nueve años, cuando murieron sus padres, sin ningún tener contacto alguno con ningún otro familiar.

Su plan de atención personal (PAP) incluye apoyos relacionados con la búsqueda de trabajo y su seguimiento, la gestión de ayudas sociales, la gestión de su vivienda, y un seguimiento cercano a nivel personal y psicológico.

En este caso, la situación de desamparo, la precariedad material y una alta fragilidad emocional provocaban una relación de dependencia con el servicio de referencia. Por estos motivos se valoró que la asistencia podía suponer una nueva ayuda complementaria que aumentara los apoyos disponibles.

En el proceso de derivación de la persona solicitante formuló demandas referidas a:

- Ayuda en las relaciones con las Administraciones públicas.

- Acompañamiento en la firma de contratos de trabajo y en su ejecución, velando por sus derechos y siendo el asistente el interlocutor en las relaciones con la empresa o entidad para la que preste sus servicios profesionales.

- Ayuda en la búsqueda de prestaciones sociales a las que pueda tener derecho.

Caso C: El último caso seleccionado se trataba de una persona de 29 años de edad, con un diagnóstico de discapacidad intelectual, hidrocefalia y problemas de salud física, con un grado de disminución reconocido del $65 \%$ que vive sola hace años, desde que su madre se trasladó a otra comunidad autónoma, con la que mantiene contactos ocasionales.
Derivada por los servicios sociales, su plan de atención personal (PAP) elaborado e iniciado hace cinco años por el servicio de de vida independiente incluía apoyos relacionados con la gestión económica, de prestaciones sociales, de varias deudas acumuladas, la búsqueda de vivienda, de formación profesional y de trabajo y un seguimiento intenso debido a distintos problemas de salud física y mental.

En este caso, la solicitud de asistencia se concretó en referencia a:

- Ayuda en la tramitación de la aceptación de una supuesta herencia familiar.

- Ayuda en el pago y amortización de deudas pendientes.

- Ayuda en la tramitación de prestaciones sociales a las que tuviera derecho.

20. Tramitación de las demandas de los solicitantes

Una vez confirmadas y formuladas las demandas de asistencia de los tres casos seleccionados por parte de los servicios jurídicos, los solicitantes fueron citados en el Juzgado pertinente. A diferencia de los procesos de incapacitación legal, en este caso el Juez y el médico forense solamente atendieron a la única declaración de la propia persona interesada y la información extraída de la documentación presentada.

Esencialmente, en las declaraciones se hizo mucha insistencia en preguntar los motivos por los cuales la persona solicitaba la asistencia, confirmar que no hubiera indicios de influencia externa en la demanda personal, confirmar también la identidad de los futuros asistentes propuestos y la conciencia de las consecuencias del acto jurídico en curso.

Por otro lado, el órgano judicial confirmó con la entidad tutelar del proyecto su conformidad con la futura aceptación de la asistencia del solicitante. 
La duración media de la tramitación de las demandas osciló entre los 6 y 9 meses. Durante este periodo, el equipo del proyecto piloto mantuvo un seguimiento continuo con los solicitantes que permitió mantenerlos informados de todo el proceso, empezar a desarrollar la concreción de los futuros apoyos de la asistencia e ir construyendo una relación de confianza per permitiera iniciar la provisión asistencia de una manera adecuada, llegado el momento.

\section{Resultados de las resoluciones y nombramientos}

De las demandas presentadas, dos casos tuvieron una sentencia judicial favorable al nombramiento de los asistentes y una denegatoria.

En los casos favorables, la sentencia determinaba las funciones de la asistencia en la esfera patrimonial, referida a la administración de bienes, por los motivos expuestos en las correspondientes demandas (realización de la declaración del IRPF, actuaciones ante las administraciones públicas, solicitud de prestaciones y ayudas sociales, a excepción de la demanda de orientación para preparar el otorgamiento de testamento, atendido el carácter personalísimo de este acto de última voluntad para el que no se requiere un pronunciamiento judicial. De las funciones relativas al patrimonio, el asistente debe rendir cuentas anuales al juzgado.

Y en la esfera personal las sentencias determinaban funciones referidas a velar por el bienestar personal a partir de las demandas que la persona asistida pudiera formular a su asistente, junto con otras más explícitas como prestar consentimiento informado en caso de no disponer de un documento de voluntades anticipadas.

En ambos casos, se confirmó el pacte individual de asistencia que ha permitido planificar y proveer los apoyos previstos en las funciones de la asistencia. Asimismo la aplicación de la asistencia se coordinó con los servicios asistenciales de referencia para garantizar la complementariedad y adecuación de los apoyos previstos gracias al trabajo en red realizado.

En un caso, la demanda fue rechazada apelando a la falta de confirmación de las voluntades del solicitante como factor determinante de todo el proceso de solicitud, valoración, aceptación o extinción de la asistencia. Las limitaciones de las capacidades cognitivas y volitivas que se evidenciaron en algunas declaraciones y contradicciones de la solicitante durante la vista, hicieron que el juez negara la conveniencia de la asistencia como medida de protección.

\section{Algunas conclusiones}

Los resultados de este proyecto piloto evidencian la viabilidad de esta nueva medida de protección legal como alternativa a los procesos de incapacitación legal.

Asimismo, es del todo necesario experimentar esta figura con el máximo de casos posibles para poder disponer de datos que permitan validar las posibilidades y los límites que ofrece.

A finales de 20I4, en Catalunya se registraron I 8 casos de personas acogidas a la asistencia por parte de entidades tutelares pero se desconoce la cifra de los casos en los que se haya demandado y nombrado a personas físicas como asistentes.

Al tratarse de una figura que coexiste con la tutela y la curatela con supuestos y regulaciones distintas, debemos explorar aquellas características y/o circunstancias que permitan orientar cada una de estas medidas de protección. Ampliar los recursos de protección de las personas exige desarrollar criterios para poder orientar y apoyar decisiones en este sentido.

Es necesario hacer la máxima difusión de la asistencia con una información que permita a 
las personas interesadas y sus referentes valorar la conveniencia de acogerse a esta $u$ otras medidas de protección legal. Mientras no sea así, seguirán prevaleciendo medidas como la tutela o la curatela que implican la modificación de la capacidad de la persona. Ello quizás sea necesario en algunos casos pero debemos procurar la individualización y adecuación de las medidas a las necesidades y las voluntades reales de cada persona.

La misma difusión debe hacerse con los órganos judiciales y colegios de abogados para dar a conocer la incidencia de su aplicación en nuestro territorio, de manera que se consolide como una verdadera opción a la incapacitación legal.

La creciente aplicación de la asistencia permitirá iniciar el análisis de la regulación de las fórmulas de protección legal de las personas con discapacidad en nuestro país. No menos importante es la revisión de cómo aplican estas medidas de protección los asistentes, sean personas físicas o jurídicas, mediante procedimientos y protocolos que orienten su ejercicio hacia las buenas prácticas, el fomento de la autonomía personal y la defensa de sus derechos. 


\section{Referencias bibliográficas}

Naciones Unidas (2006). Convención Internacional sobre los Derechos de las Personas con Discapacidad (en línea). ‘http://www.un.org/ spanish/disabilities/default.asp id=497>.

Catalunya. Llei 25/2010, del 29 de juliol, del llibre segon del codi Civil de Catalunya, relatiu a la persona i la família. Diari Oficial de la Generalitat de Catalunya, 5 d'agost de 20I0, núm. 5686.

Follia, R. (20I2): "La defensa de la dignidad de la persona en el libro II del Código civil de Cataluña. Medios para su protección”. La Notaria, (2): 36-43.

Inclusion International (20I4). Independiente pero no solo. Informe mundial sobre el derecho a decidir. Canadá: Is five Communications.

Martín, J.A. (20I I): “La asistencia como alternativa a los instrumentos tradicionales de protección de las personas con discapacidad.
Notas sobre el nuevo derecho de personas en Cataluña”, en R. Barrada Orellana, et al. (coord.): El nuevo Derecho de la persona y de la familia: Libro Segundo del Código Civil de Cataluña. Barcelona: Bosch.

Padial, A. et al. (2010): "La protección de las personas discapacitadas en el Libro II del Codi Civil de Catalunya, relativo a la persona y la familia”, en S. de Salas Murillo (coord.): Hacia una visión global de los mecanismos jurídico-privados de protección en materia de discapacidad. Zaragoza: El Justicia de Aragón.

Pereña, M. (20Iо) “Autonomía y voluntad en la dependencia y la incapacidad “. En: Jornadas DINCAT, (Barcelona 22 de Octubre de 2010), [S.l.]: [s.n.].

Ribot Igualada, J. (20I2) "L'assistència: abast i limitacions de la nova institució". En: XVIIenes Jornades de Dret Català a Tossa, (Tossa de Mar, septiembre de 20I2). [S.1.]: [s.n.]. 